\title{
Monitoring, analysis and modeling of yield and quality dynamics of Lolium perenne varieties for biogas production
}

\author{
Swieter, A. ${ }^{1}$, Moenickes, S. ${ }^{2,3}$, Greef, J.-M. ${ }^{1}$ \\ ${ }^{1}$ Julius Kühn-Institut, Institute for Crop and Soil Science, Braunschweig \\ ${ }^{2}$ Technische Universität Braunschweig, Institute of Geoecology, Braunschweig \\ ${ }^{3}$ Hochschule Rhein-Waal, Fakulty of Life Science, Kleve \\ Email of corresponding author: Anita.swieter@jki.bund.de
}

The overall aim of this project is to increase the biogas production of perennial ryegrass (Lolium perenne) by model-based optimization of the harvesting date. In a preliminary step it was analyzed statistically, whether the harvesting date influences yield and quality of $L$. perenne varieties. In a second step a model for yield and quality development of the varieties was set up and parameterized.

In the first step 20 varieties of $L$. perenne differing in maturing times were cultivated at five sites in Germany and the Netherlands. Two harvesting treatments were applied: consistent harvest $\left(H_{c}\right)$, where all varieties were harvested at the same time, as it is common practice, and differentiated harvest $\left(H_{d}\right)$, where each variety was harvested at growth stage of ear emergence. Yield was characterized as dry matter yield, and quality parameters, such as crude protein and crude fiber, were determined by Near Infrared Spectroscopy (NIRS). Yield and quality data were analyzed descriptively and by ANOVA. It was shown that yield and grass quality varied mainly between site and year. A significant interaction between variety and harvesting treatment indicated, that yield and quality of both harvesting treatments differed particularly between the early and late varieties: Yield of early varieties was greater in $\mathrm{H}_{c}$, while yield of late varieties was lower in $\mathrm{H}_{c}$ than in $\mathrm{H}_{\mathrm{d}}$. On the contrary, quality of early varieties was lower in $\mathrm{H}_{c}$, while quality of late varieties was greater in $\mathrm{H}_{c}$ than in $\mathrm{H}_{\mathrm{d}}$.

In the second step, a logistic growth model for yield and quality development was set up, which also includes the most important environmental conditions, such as temperature and soil moisture. For model parameterization, eight $L$. perenne varieties with different maturing times were cultivated at four locations in Germany and harvested in time series. Yield and quality of $L$. perenne and environmental conditions were monitored. The model fitted well to both, yield and quality data of $L$. perenne varieties at all sites. The differences in yield and quality development were reflected by the model through differences in rates of growth and temperature coefficients: Early varieties had lower rates of growth and temperature coefficients than late varieties.

It can be concluded, that this model can help to characterize $L$. perenne varieties and determine the optimal date of harvest for an increased biogas production. 